\title{
Research on the Current Situation of Sports Consumption of Students from College of Oujiang
}

\author{
Jun Chen*
}

College of Oujiang, Wenzhou University, Wenzhou 325035, Zhejiang, P.R. China

\begin{abstract}
In order to establish a correct consumption concept on sports and build up a reasonable and scientific sports consumption structure for the students from College of Oujiang, the paper conducts the research on the consumption situation and level of the Oujiang students with such methods as documentation, questionnaire and mathematical statistics. With the Students who start their college from 2011 to 2014 as the objects, the results are as follows: There is a rational consumption structure and clear consumption intent from the students, which is positive and healthy. And then, the consumption for material objects accounts for a lot and there is a rapid increase for service. However, family economic ability, prices and consumption environment also affect and constrain the expense level of Oujiang students on sports consumption. Meanwhile the paper also puts forward some suggestions and methods to the education and guiding work to the students in the consumption on sports.
\end{abstract}

Keywords: College of oujiang, consumption on sports, current situation, engel coefficient.

\section{INTRODUCTION}

Modern students who hold a high cultural quality, deep thinking and a strong subject consciousness compose the new consuming group. They have unique insights different from other consumer groups and their own consumption patterns suitable to themselves, and represent a new consumption concept in the new era. Their awareness and behaviors will not only display a direct impact on their own health, but also will show a demonstration for the surrounding groups even for the whole nation. Therefore, it will be beneficial to the healthy growth of college students and present a good role model on the social sports consumption to pay attention to the new changes in students' sports consumption attitudes, of college students and guide them to establish a correct concept of consumption: "future and reality, utility and leisure, individuality and diversity, harmony and unity" [1-3].

College of Oujiang, an independent college from Wenzhou University, was approved by the Education Ministry in 2004. Located at the higher education park, it holds about 8,000 students at school and has a teaching area of 680 $\mathrm{mu}$ (about 112 acres) and a total sports playground area of 73,660 sqms with an average of 9.2 sqms per student. The college is all above average in Zhejiang Province in terms of school location, surrounding economy and cultural environment. Currently, the research on students' consumption on sports is only limited to the first-class and second-class universities in the advanced cities and few is on the students from the independent college in Zhejiang Province. So the paper will be representative for the independent colleges in the province even the whole nation. There in a creasing growth in the fitness facilities and exercising members over years, so it's more important to do a specific research with the consumption pattern of students more and more diversified $[4-8]$.

\section{OBJECT AND METHODS}

\subsection{Object}

700 boys and 300 girls from those starting their college from 2011 to 2014 have been selected randomly.

\subsection{Methods}

\subsubsection{Documentation}

11 documents related to sports economy and consumption, one sports industry book and 3 relative graduation papers have been checked and learnt.

\subsubsection{Questionnaire}

Based on documentary and interviews, a questionnaire is designed, which is suitable to students' current consumption situation. And the reliability and validity have been checked with following results Table $\mathbf{1}$.

\subsubsection{Interview}

Students are interviewed at sports area in 4 relative places (gym, athletic field, dormitory neighborhood, teaching buildings).

\subsubsection{Mathematical Statistics}

Data is worked out with Excel from tables and figures and a $\mathrm{U}$ and $\mathrm{X} 2$ check is conducted with the coefficient above $0.93(\mathrm{P}<0.01)$, which tells a high reliability of the research. 
Table 1. Random selection of the researched objects.

\begin{tabular}{|c|c|c|c|c|c|}
\hline $\begin{array}{c}\text { School } \\
\text { Starting } \\
\text { year }\end{array}$ & $\begin{array}{c}\text { Actual dis- } \\
\text { tributed cop- } \\
\text { ies }\end{array}$ & $\begin{array}{c}\text { Taken } \\
\text { back } \\
\text { copies }\end{array}$ & $\begin{array}{c}\text { Effective } \\
\text { copies }\end{array}$ & $\begin{array}{c}\text { Taking } \\
\text { back rate } \\
\text { (\%) }\end{array}$ & $\begin{array}{c}\text { Effective } \\
\text { rate (\%) }\end{array}$ \\
\hline \hline 2011 & 200 & 181 & 165 & 90.5 & 91.1 \\
\hline 2012 & 275 & 256 & 242 & 93.0 & 94.5 \\
\hline 2013 & 275 & 260 & 255 & 94.5 & 98.0 \\
\hline 2014 & 250 & 245 & 239 & 98.0 & 97.5 \\
\hline Total & 1000 & 942 & 901 & 94.2 & 95.6 \\
\hline
\end{tabular}

\section{RESULTS AND ANALYSIS}

\subsection{Definition and Current Features of Sports Consump- tion}

Sports consumption refers to the expense on using and consuming sports means while participating and watching sports games, purchasing real sports materials or enjoying sports services to meet the sports needs. It includes real material consumption and intangible services consumption. And the sports consumption structure is the proportion relation within different kinds on consuming means under certain social and economic conditions. According to relative documentary, the sports consumption structure of our urban residents can be seen from the following figure.

Moreover, the current sports consumption is mainly based on practical utility and the price of sports materials is around 100, most of which are durable goods. With the popularization of some sports activities and the improvement

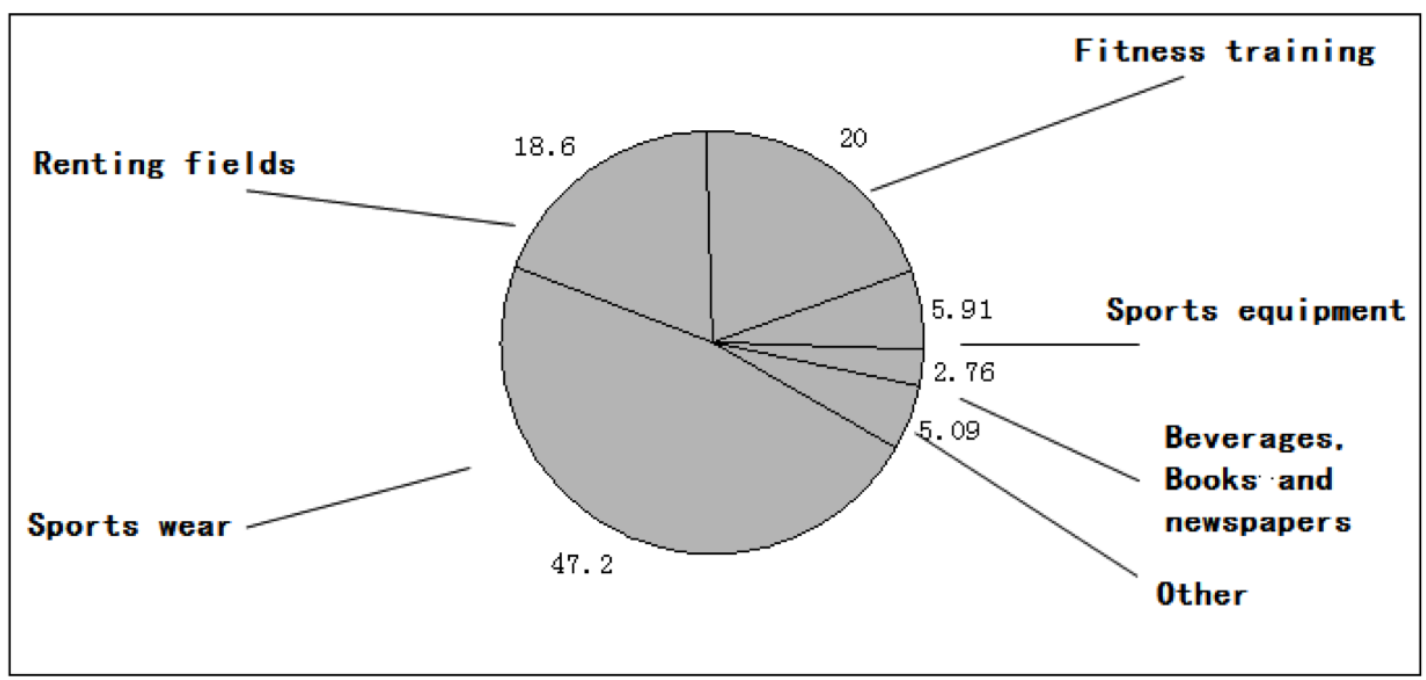

Fig. (1). Sports consumption structure of Chinese urban residents.

Table 2. Current situation of students' sports consumption level.

\begin{tabular}{|c|c|c|c|c|c|c|}
\hline \multirow{2}{*}{$\begin{array}{c}\text { Consumption level } \\
\text { (Yuan/month) }\end{array}$} & \multicolumn{2}{|c|}{ Male } & \multicolumn{2}{c|}{ Female } & \multicolumn{2}{c|}{ Total } \\
\cline { 2 - 7 } & $\mathbf{n}$ & $\%$ & $\mathbf{n}$ & $\%$ & $\mathbf{n}$ & $\%$ \\
\hline \hline Zero & 16 & 1.86 & 36 & 7.13 & 52 & 3.85 \\
\hline below 50 & 63 & 7.31 & 45 & 9.12 & 108 & 7.97 \\
\hline $50-100$ & 216 & 25.25 & 108 & 21.61 & 324 & 23.91 \\
\hline $101-200$ & 478 & 55.83 & 278 & 55.82 & 756 & 55.79 \\
\hline above 200 & 84 & 9.75 & 31 & 6.32 & 115 & 8.48 \\
\hline Total & 857 & 100.0 & 498 & 100.0 & 1355 & 100.0 \\
\hline
\end{tabular}


of sports technologies, students hold a higher and higher demand for sports facilities, suits and shoes, so the consuming level is creasing. From the research, we can tell the prices from 50 to 100 account a lot in their consumption Table 2.

\subsection{Current Consumption Situations of Oujiang Stu- dents and Influential factors}

\subsubsection{Current Sports Consumption Situations of Oujiang Students}

The current sports consumption level of our students can be told from Table 3. No students spends nothing on sports and there is 3.68 percent points higher than the national level within 0-50, 5.52 higher within 50-100, 5.98 lower within 100-200 and 3.22 lower above 200. The statistics above shows sports material with lower price such as suits and shoes take the primary place in students' consumption. And there is a little pursuit for the high-priced sports materials or maybe there is a lack of the accumulation for sports consumption.

Reasons: The above situations are mainly given birth by the location of our college and the surrounding sports industry development as well as the different attitudes of students towards sports consumption. Compared with other big and medium-sized cities, Wenzhou has lots of high-class sports malls and markets but there is limited consumption by college students. And small and medium-sized markets in Wenzhou are relatively advanced, which is more suitable to students who prefer good products with low prices. So, there are much higher points for our students within 0-50 and 50100 . In addition, there is a lack of sports culture publicity, the understanding and recognition of sports consumption in our college or sports consuming accumulation, which lead to the fact of principal low-priced consuming and subordinate high-priced purchasing $[9,10]$.

From above, we can tell there is a combination of real materials and services of the sports consumption structure with a diversified development of our students. Table 4 shows that consumption for real material goods accounts for the main part, and compared with figure 1 , there are 13.3 percent points higher on sportswear consumption than other college students, 12.09 higher on sports equipment, 1.84 higher on sports books, 11.5 percentage points lower in ground rents, and 10.5 lower on training and exercise. And the consumption is relatively low in other aspects, such as tickets, lottery tickets, tours or more advanced sports consumptions. The purchase of sports labor or services and sports activities only accounts for $21.5 \%$ and there is a wide gap between participative consumption and real material consumption [11]. The main reason is the lack of consumption environment in our college, which leads to the single consumption way. Besides, the matched facilities and the corresponding services are lagging behind; for instance, in the urban area or within our campus, there is a shortage of formal training facilities and institutions or major matches and games because of the limited sports ground. Then the

Table 3. Average consumption level per month of Oujiang students (yuan/month).

\begin{tabular}{|c|c|c|c|c|c|c|c|c|c|c|c|}
\hline \multirow{2}{*}{$\begin{array}{c}\text { Consumption } \\
\text { level }\end{array}$} & \multirow{2}{*}{ Gender } & \multicolumn{2}{|c|}{2011} & \multicolumn{2}{|c|}{2012} & \multicolumn{2}{|c|}{2013} & \multicolumn{2}{|c|}{2014} & \multicolumn{2}{|c|}{ Total } \\
\hline & & $\mathbf{n}$ & $\%$ & $\mathbf{n}$ & $\%$ & $\mathbf{n}$ & $\%$ & n & $\%$ & n & $\%$ \\
\hline \multirow{2}{*}{ zero } & M & 0 & 0 & 0 & 0 & 0 & 0 & 0 & 0 & \multirow{2}{*}{0} & \multirow{2}{*}{0} \\
\hline & $\mathrm{F}$ & 0 & 0 & 0 & 0 & 0 & 0 & 0 & 0 & & \\
\hline \multirow{2}{*}{ Below 50} & M & 19 & 15.4 & 20 & 15.4 & 18 & 14.1 & 19 & 15.4 & \multirow{2}{*}{139} & \multirow{2}{*}{15.5} \\
\hline & F & 16 & 16.3 & 17 & 17.0 & 15 & 14.7 & 15 & 16.0 & & \\
\hline \multirow{2}{*}{$50-100$} & M & 36 & 29.3 & 40 & 30.8 & 38 & 29.7 & 37 & 30.1 & \multirow{2}{*}{264} & \multirow{2}{*}{29.43} \\
\hline & F & 29 & 29.6 & 27 & 27.0 & 29 & 28.4 & 28 & 29.8 & & \\
\hline \multirow{2}{*}{$100-200$} & M & 59 & 48.0 & 62 & 48.6 & 62 & 48.4 & 60 & 48.8 & \multirow{2}{*}{448} & \multirow{2}{*}{49.81} \\
\hline & $\mathrm{F}$ & 50 & 51.0 & 53 & 53.0 & 53 & 52.0 & 49 & 52.1 & & \\
\hline \multirow{2}{*}{ above 200} & M & 9 & 7.3 & 8 & 6.2 & 10 & 7.8 & 7 & 5.7 & \multirow{2}{*}{47} & \multirow{2}{*}{5.26} \\
\hline & $\mathrm{F}$ & 3 & 3.1 & 3 & 3.0 & 5 & 4.9 & 2 & 2.1 & & \\
\hline
\end{tabular}

Table 4. Consumption structure of Oujiang students (yuan/month).

\begin{tabular}{|c|c|c|c|c|c|c|c|}
\hline $\begin{array}{c}\text { Purchased } \\
\text { materials }\end{array}$ & $\begin{array}{c}\text { Sports } \\
\text { suits }\end{array}$ & $\begin{array}{c}\text { Sports } \\
\text { equip- } \\
\text { ments }\end{array}$ & $\begin{array}{c}\text { Sports } \\
\text { books }\end{array}$ & $\begin{array}{c}\text { Ground } \\
\text { Rents }\end{array}$ & $\begin{array}{c}\text { Fitness } \\
\text { classes }\end{array}$ & $\begin{array}{c}\text { Sports } \\
\text { lottery }\end{array}$ & $\begin{array}{c}\text { Matches } \\
\text { tickets }\end{array}$ \\
\hline \hline $\mathrm{X} \pm \mathrm{S}-$ & $50 \pm 1.2$ & $15 \pm 0.6$ & $4 \pm 0.2$ & $6 \pm 0.2$ & $8 \pm 0.1$ & $0.1 \pm 0.01$ & $0.1 \pm 0.01$ \\
\hline$\%$ & 60.5 & 18.0 & 4.6 & 7.1 & 9.5 & 0.20 & 0.1 \\
\hline
\end{tabular}


Table 5. Consumption motives of Oujiang students.

\begin{tabular}{|c|c|c|c|c|c|c|c|c|c|c|c|c|c|c|c|c|c|c|}
\hline \multirow[t]{2}{*}{ Grade } & \multicolumn{2}{|c|}{ Recreation } & \multicolumn{2}{|c|}{$\begin{array}{c}\text { Health } \\
\text { improving }\end{array}$} & \multicolumn{2}{|c|}{$\begin{array}{c}\text { Body } \\
\text { building }\end{array}$} & \multicolumn{2}{|c|}{$\begin{array}{l}\text { Physical } \\
\text { tests }\end{array}$} & \multicolumn{2}{|c|}{$\begin{array}{l}\text { Campus } \\
\text { love }\end{array}$} & \multicolumn{2}{|c|}{$\begin{array}{c}\text { Compari- } \\
\text { son pur- } \\
\text { suing }\end{array}$} & \multicolumn{2}{|c|}{$\begin{array}{l}\text { Extracurricu- } \\
\text { lar Richening }\end{array}$} & \multicolumn{2}{|c|}{$\begin{array}{c}\text { Knowl- } \\
\text { edge } \\
\text { acquiring }\end{array}$} & \multicolumn{2}{|c|}{$\begin{array}{c}\text { Blind } \\
\text { consump- } \\
\text { tion }\end{array}$} \\
\hline & $\mathbf{n}$ & $\%$ & $\mathbf{n}$ & $\%$ & $\mathbf{n}$ & $\%$ & $\mathbf{n}$ & $\%$ & $\mathbf{n}$ & $\%$ & $\mathbf{n}$ & $\%$ & $\mathbf{n}$ & $\%$ & $\mathbf{n}$ & $\%$ & $\mathbf{n}$ & $\%$ \\
\hline 11 & 32 & 19.3 & 45 & 27.2 & 28 & 17.1 & 10 & 6.2 & 11 & 6.8 & 6 & 3.5 & 11 & 6.4 & 15 & 9.5 & 5 & 3.0 \\
\hline 12 & 44 & 18.2 & 61 & 25.4 & 40 & 16.7 & 18 & 7.5 & 12 & 5.1 & 14 & 5.7 & 21 & 8.9 & 21 & 8.7 & 9 & 3.7 \\
\hline 13 & 50 & 19.7 & 58 & 22.8 & 33 & 12.9 & 37 & 14.6 & 12 & 4.9 & 12 & 4.8 & 20 & 7.9 & 22 & 8.6 & 9 & 3.8 \\
\hline 14 & 52 & 21.8 & 51 & 21.3 & 32 & 13.4 & 40 & 16.8 & 11 & 4.8 & 9 & 3.7 & 16 & 6.8 & 16 & 6.8 & 11 & 4.6 \\
\hline total & 148 & 19.7 & 215 & 24.0 & 133 & 14.7 & 105 & 12.4 & 46 & 5.2 & 41 & 4.2 & 68 & 7.6 & 74 & 8.4 & 34 & 3.8 \\
\hline
\end{tabular}

lottery outlets haven't developed into the campus, which all affect the development of sports consumptions of our college altogether.

\subsubsection{Consumption Motives and Influential Factors}

From Table 5, we can see that the main motives of students' sports consumptions are to enhance physical health, recreation and bodybuilding, which is positive, optimistic and upward on whole. But to acquire knowledge is a relatively small motive, which will inevitably affect the exercise effects. Sports, the comprehensive discipline, ask much more than enthusiasm; sports knowledge and scientific methods are much more important to achieve the best results. A considerable amount of low-grade students get a blind concept to sports consumption, which will inevitably lead to the greatest benefits absence of the limited physical consumption funds.

From Table $\mathbf{6}$ and Table 7, we can see that the factors affecting sports consumption can be concluded as follows: first is the family economic ability; then it's the high prices and the lack of consuming environment. College students almost completely depend on their parents for a living during their college days. And according to Engel's Law, the lower the family income is, the lower the total expense is and the more the expense on food is. With the increase of family income, the expense on food from the total will be going down while the expense on recreation will be going up. So, the sports consumption which can be counted as a high-level and recreation-oriented consumption will be put behind when their economic sources got limited. Then, high pries is a common influential factor, which is about at the same level as the whole nation. The writer agrees some sports products and services really have high price but low-quality. However, the reasons leading to the thinking above is the absence of enough knowing and understanding for sports consumption value. Affected by the traditional consumption concept, students now hold inadequate knowing and understanding for the consumption value, which display an impact on the development of sports consumption. Additionally, there is limited sports consumption at or surrounding the location of our campus, which means the lack of consumption environment, is an important influential factor. As for free time, our students get a lot, and that is to say the class schedule design is reasonable and students get enough time to work out. But on the other side, it means there should be stricter control on their studies. 
Table 7. Influential factors for sports consumption of Chinese college students.

\begin{tabular}{|c|c|c|c|c|c|c|}
\hline Gender & $\begin{array}{c}\text { Heavy } \\
\text { school } \\
\text { work }\end{array}$ & $\begin{array}{c}\text { Lacking } \\
\text { eco- } \\
\text { nomic } \\
\text { sources }\end{array}$ & $\begin{array}{c}\text { Gyms } \\
\text { shortage }\end{array}$ & $\begin{array}{c}\text { No } \\
\text { interest }\end{array}$ & $\begin{array}{c}\text { High } \\
\text { price }\end{array}$ & Others \\
\hline \hline male & 29.3 & 8.4 & 21.3 & 6.1 & 31.2 & 3.7 \\
\hline female & 31.8 & 7.3 & 17.9 & 9.7 & 24.7 & 8.6 \\
\hline
\end{tabular}

Note: Table 7 is quoted from Research on the Current Situation on Sports Consumption of College Students [J] by Hu Wenxin and Yu Tianbo.

\subsubsection{Sports Consumption Differences between Different Grades and Genders and Reasons}

There is little difference between boys and girls with respect to the consumption on sportswear, shoes and equipments. The difference is boys spend more on sports information and games but they spend less on the ground rents since they usually play basketball and soccer whose ground is often for free. While for girls, they prefer calisthenics, badminton, tennis and swimming which should be done indoor or demand specialized ground and training staff. So girls' expense goes to the above-mentioned quick-wearing equipments. Besides, girls like travelling but show little interest in acquiring sports information and watching games. Those above are the general differences between boys and girls. So, by and large, the expense by boys is generally higher than girls and the expense goes up as the grade does (see Fig. 2).

\section{CONCLUSIONS AND SUGGESTIONS}

\subsection{Conclusions}

(1) There is a clear and definite motive for Oujiang students to conduct sports consumptions, which is positive and healthy.

(2) On whole, the consumption level is increasing and expense on real material is more than that on sports services. In addition, real material proportion is larger than other areas and the services proportion is rapidly going up, though it's smaller compared to other areas in China. And it must be closely connected with the economic growth and sports cultural popularization of Wenzhou city as well as the construction of new gyms at our college.

(3) Major factors that stimulate students' sports consumption can be concluded as recreation, health-keeping and bodybuilding; Principal factors affecting their consumption level are family economic ability, prices and consumption environment. Yet, some students are motivated by comparison, flaunt and some spend money blindly. Few students spend a lot on sports knowledge acquiring.

Table 6. Influential factors for sports consumption of Oujiang students.

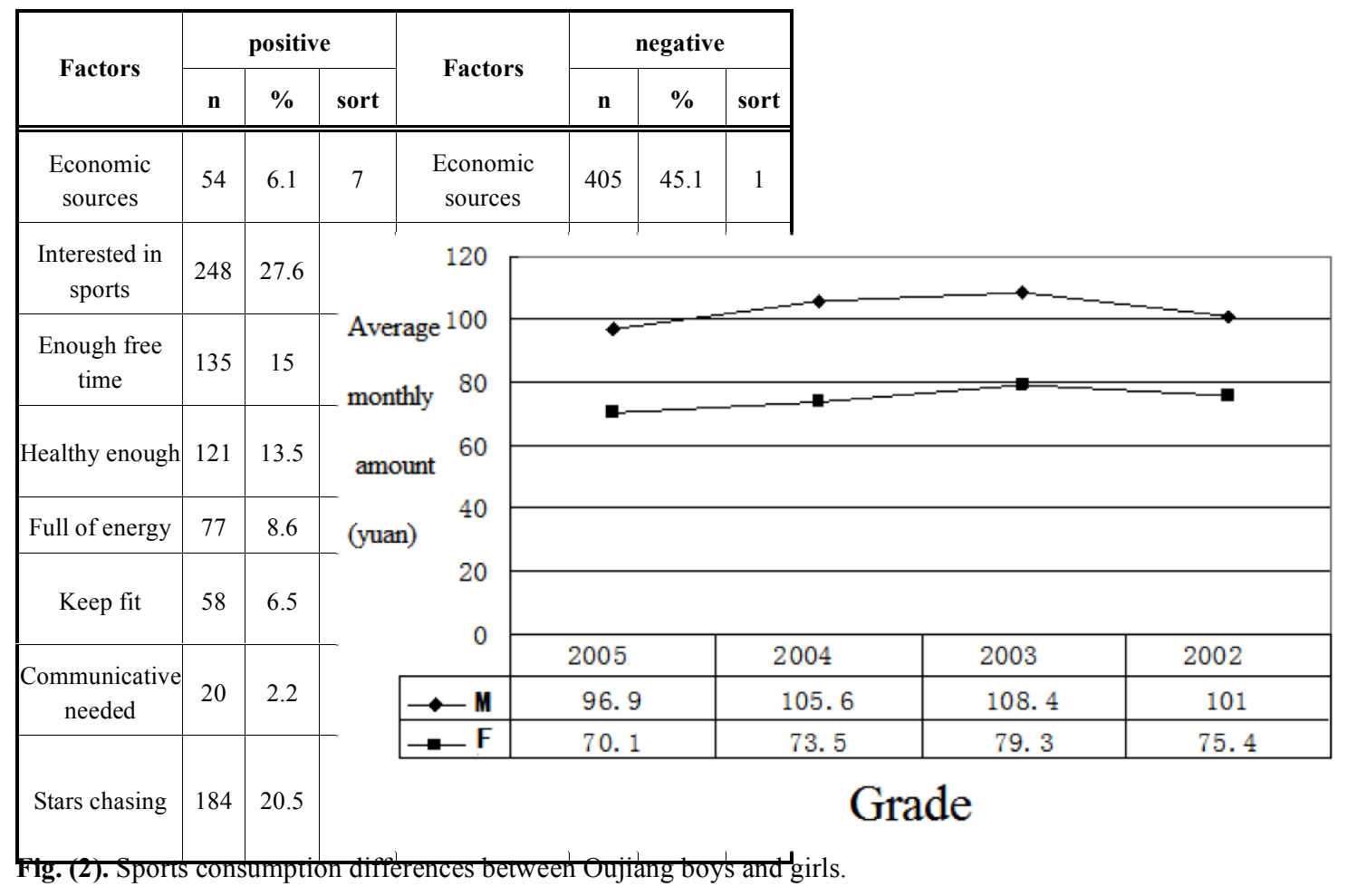


(4) Boys spend more on sports than girls and the higher the grade is, the more the expense is. It's easy for the students in lower grades to make some unclear and blind consumption, and their understanding for sports functions is growing to be reasonable grade increasing.

\subsection{Suggestions}

\subsubsection{Publicity Enhancing and Correct Guidance}

The publicity of sports consumption should be enhanced and correct guidance should be done to our students. Then, newspaper, broadcast and propaganda columns should be employed to spread the sports knowledge and scientific common sense. Thus, the students will be exposed to the principle of "health-first" and aware of the meanings of sports consumption and transform the attitudes towards it.

\subsubsection{Market Planning and Facilities Improving}

Design, supervision and management of sports market in Wenzhou city and our college should be improved to increase the consumption level of our students. Efforts can be made to spread sports consumption concept, subdivide the market and improve the quality of sports facilities and gyms while paying attention to the levels of development. It's also necessary for teachers to teach some sports common sense and channels to participate in sports activities so as to strengthen their awareness of sports consumption. At the same time, more sports-related service sites should be built such as fitness counseling center and associations of balls and exercises.

\subsubsection{Potential Exploring and Concept Strengthening}

The economic potential of sports in our college should be explored; the advantages of sports facilities and surrounding environment should be fully taken; while ensuring students' chances to exercise, college gyms and facilities can be opened to the outside to attract social investment in our sports cause. To boost the sports development of our college, paid sports activities and sports materials can be offered within or around the campus and students should be encouraged to participate more in sports programs at the same time. The sports consumption concept of our students can be guided and corrected through PE classes and speeches on sports theories, which can enable them to build the consumption idea of "sports consumption for personal health and social civilization". Finally, those conducting consumptions blindly or motivated by comparison and flaunt can be reasonably led.
While focusing on the research on girls' physical education, efforts can also be made to promote such femalesuitable sports programs and classes as calisthenics, gymnastics, table tennis, shuttlecock, badminton and tennis. Sports programs can be carried out through interesting games and the cooperation of girls and boys so as to explore girls' potential and encourage them to be more active in sports and promote healthy and positive sports consumption in the end.

\section{CONFLICT OF INTEREST}

The authors confirm that this article content has no conflicts of interest.

\section{REFERENCE}

[1] E. Thibaut, S. Vos, and J. Scheerder, "Hurdles for sports consumption? The determining factors of household sports expenditures," Sport Management Review, vol. 17, no. 4, pp. 444-454, 2013.

[2] S. C. Kong, "Developing information literacy and critical thinking skills through domain knowledge learning in digital classrooms: An experience of practicing flipped classroom strategy," Computers \& Education, vol. 78, pp. 160-173, 2014.

[3] L. Nielsen, "Five reasons i'm not flipping over the flipped classroom," En, 3210, 2012.

[4] W. De Sarbo, and Madrigal, Robert. "Exploring the Demand Aspects of Sports Consumption and Fan Avidity," En, vol. 42, no. 2, 2012.

[5] X. Lei, and H. Yu, "The quantitative analysis on the individual characteristics of urban residents and their sport consumption motivation," Physics Procedia, vol. 33,pp.15-30, 2012.

[6] L. Y. Wu, "investigation and analysis on sports consumption of urban residents of henan province," Physics Procedia, vol. 33, 2012.

[7] A. J. Karg, and H. McDonald, "Fantasy sport participation as a complement to traditional sport consumption," Sport Management Review, vol. 14, no.4, pp. 327-346, 2011.

[8] A. Decrop, and C. Derbaix, "Pride in contemporary sport consumption: a marketing perspective," Journal of the Academy of Marketing Science, vol. 38, no. 5, pp. 586-603, 2010.

[9] P. Wicker, J. Prinz, and D. Weimar, "Big spenders in a booming sport: consumption capital as a key driver of triathletes' sportrelated expenditure," Managing Leisure, vol. 18, no. 4, 2013.

[10] Rei Saito, Munehiko Harada, Morikazu Hirose. "The Scale Development for Experiential Value Scale for Sport Consumption (EVSSC) and fan segmentation in J-League team," Japanese Journal of Sport Management, vol. 2, vo.1, pp. 3-17, 2010.

[11] Dae Hee Kwak, Joon-Ho Kang. "The effect of self/team follower image congruence on spectator sport consumption behavior and team loyalty," International Journal of Sport and Health Science, vol. 6, pp. 135-144, 2008.

\subsubsection{Coordinated Development and More Attention to Girls}

Received: June 10, 2015 